\title{
Prevalence and preventability of sentinel events in Saudi Arabia: analysis of reports from 2012 to 2015
}

Salem Al Wahabi ${ }^{1}$, Fayssal Farahat ${ }^{2}$ and Ahmed Y. Bahloul'

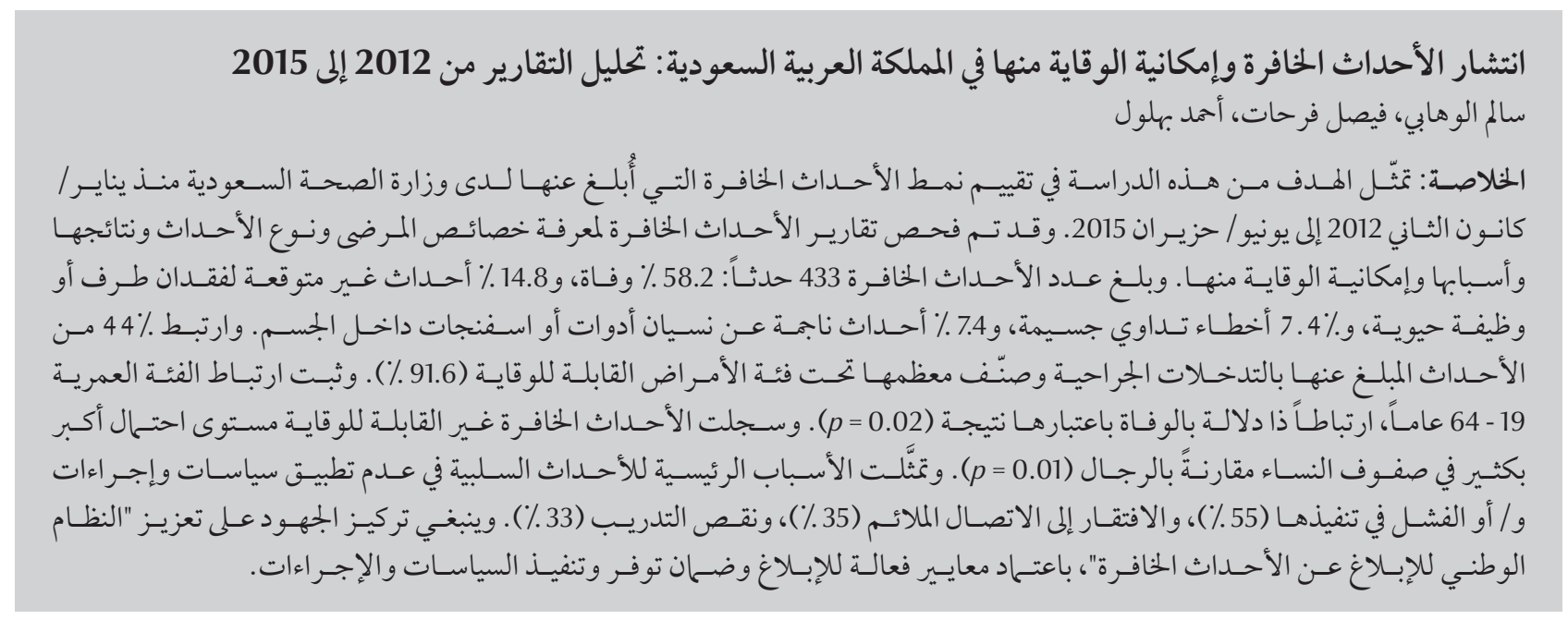

ABSTRACT This study aimed to assess the pattern of sentinel events reported to Ministry of Health of Saudi Arabia from January 2012 to June 2015. Sentinel event reports were examined for patient characteristics, type of event, outcome, cause and preventability. There were 433 sentinel events: $58.2 \%$ were deaths, $14.8 \%$ were unexpected loss of a limb or a function, $7.4 \%$ major medication errors and $7.4 \%$ retained instruments or sponges. Among the reported events, $44 \%$ were associated with surgical interventions and most were classified as preventable (91.6\%). Age 19-64 years was significantly associated with death as an outcome $(P=0.02)$. Non-preventable sentinel events were significantly more likely among women than men $(P=0.01)$. Unavailability of policy and procedures and/ or failure to implement them (55\%), and lack of proper communication (35\%) and training (33\%) were the main causes for the adverse events. Efforts should focus on enhancing the National Sentinel Events Reporting System, adopting criteria for effective reporting and ensuring availability and implementation of policies and procedures.

Prévalence et possibilités de prévention des événements sentinelles en Arabie saoudite : analyse de rapports publiés entre 2012 et 2015

RÉSUMÉ La présente étude avait pour objectif d'évaluer le profil des événements sentinelles rapportés au ministère de la Santé saoudien entre janvier 2012 et juin 2015. Les caractéristiques des patients, les types d'événements, les issues, les causes et les possibilités de prévention détaillés dans les rapports sur les événements sentinelles ont fait l'objet d'un examen. Nous avons répertorié 433 événements sentinelles : 58,2\% étaient des décès, $14,8 \%$ concernaient la perte accidentelle d'un membre ou d'une fonction, $7,4 \%$ des erreurs médicamenteuses majeures et 7,4\% un oubli d'instruments ou d'éponges. Parmi les événements rapportés, 44 \% étaient associés à des interventions chirurgicales et la majorité étaient classifiés comme évitables (91,6\%). Un âge compris entre 19 et 64 ans était fortement associé au risque de décéder des suites de l'événement $(p=0,02)$. Les événement sentinelles non évitables étaient significativement plus susceptibles de toucher les femmes que les hommes $(p=0,01)$. Le manque de politiques et de procédures et/ou l'inaptitude à les appliquer ( $55 \%)$, ainsi que le manque de communication (35\%) et de formation (33\%) constituaient les causes principales d'événements indésirables. Les efforts devraient se concentrer sur l'amélioration du Système national de notification des événements sentinelles, en adoptant des critères en vue d'une notification efficace et en garantissant la disponibilité et la mise en œuvre de politiques et de procédures.

'Saudi Central Board for Accreditation of Healthcare Institutions, Riyadh, Saudi Arabia (Correspondence to: Salem Al Wahabi: salwahabi@cbahi. gov.sa). ${ }^{2}$ King Saud bin Abdulaziz University for Health Sciences, King Abdullah International Medical Research Center, King Abdul Aziz Medical City, Ministry of National Guard-Health Affairs, Jeddah, Saudi Arabia; and Department of Public Health and Community Medicine, Menoufia University, Menoufia, Egypt.

Received: 10/12/15; accepted: 23/11/16 


\section{Introduction}

A sentinel event is the most serious form of adverse event that can occur in health care. The Joint Commission's Sentinel Event Policy and Procedures defines a sentinel event as any unexpected event that reaches the patient and harms the patient seriously, either physically or psychologically, such as causing death, permanent harm or disability, or severe temporary harm requiring an intervention to sustain life. Sentinel events can be as a result of medical errors or any other risks or hazards, e.g. a fire. They require immediate investigation and response (1).

Despite increased awareness and identification of strategies to address patient safety in the past few years, medical errors and sentinel events continue to occur (1).

The reporting of incidents, including sentinel events, is essential in order to improve and maintain the quality of health care systems (2). The majority of adverse medical events are management-related and preventable (3). This finding is consistent with Edward Deming's rule, which attributes $85 \%$ of problems to the system and its processes (the majority of which are related to the complexity and nature of the system itself) and only $15 \%$ to individuals (4). This means major improvement can be made by changing systems and standardizing processes with policies and procedures, protocols and clinical practice guidelines (5). According to the Joint Commission, failing to prepare a thorough and credible root cause analysis and implement an action plan following the occurrence of a sentinel event may affect a hospital's accreditation (5).

The Ministry of Health $(\mathrm{MoH})$ in Saudi Arabia requires 12 sentinel events to be reported by public and private hospitals. The Saudi Central Board for Accreditation of Healthcare Institutions integrated the MoH's list of reportable sentinel events within the 3 rd edition of the national hospital standards in the form of 10 sentinel events. The Board's policy urges the hospitals to report the sentinel event within 5 days of its occurrence and then to report a root cause analysis and the risk reduction plan within 30 days (6).

The 10 reportable events are: unexpected death, maternal death, wrong patient, procedure or site, retained instrument or sponge, medication error leading to death or major morbidity, infant abduction or infant discharge to the wrong family, unexpected loss of a limb or a function, haemolytic blood transfusion reaction, inpatient suicide, and gas embolism (6).

To date, there have been no published studies on sentinel event surveillance in Saudi Arabia. Therefore, the aim of this study was to review and assess the patterns and root causes of the sentinel events reported to the Saudi Ministry of Health $(\mathrm{MoH})$ over 3.5 years (January 2012-June 2015). This study also assessed the preventability of the reported events. The findings of the study could encourage managers in health care to systematically tackle such events in their facilities and help policy-makers to take actions that could lead to a safer health care system in Saudi Arabia. Furthermore, the lessons learned could be useful to all health care professionals in the country.

\section{Methods}

This was a retrospective review of all events reported to the $\mathrm{MoH}$ from January 2012 to June 2015 which were given to the Saudi Central Board for Accreditation of Healthcare Institutions. The study is an analysis of data that are routinely collected as part of the surveillance programme, no personal identifiers were reported and no institutional review board approval was required. The reports were reviewed by the study investigators, including the root cause analysis reported by the hospitals for each event. A checklist was used to record data on patient characteristics, type of intervention and hospital, outcome and preventability.

The independent variables included in this study were: age, sex, type of intervention (surgical, non-surgical, delivery) and type of hospital reporting the event (government, private). The dependent variables were patient outcome as a result of the event (died, survived) and preventability of the event. Preventability was judged by the investigators based on the available clinical information that either supported the presence of an identifiable and modifiable cause of harm or the lack of adherence to guidelines.

\section{Statistical analysis}

Data were analysed using SPSS, version 20). Descriptive statistics (e.g. numbers and percentages) were used. The chisquared test was used for categorical variables. Univariable logistic regression analysis was performed to determine the likelihood of death or non-preventable sentinel event. Odds ratios (OR) and $95 \%$ confidence intervals (CI) were calculated. A $P$-value less than 0.05 was considered statistically significant.

\section{Results}

A total of 433 sentinel events were reported from January 2012 to June 2015. Figure 1 shows types of sentinel events reported. The main types of events reported were death (unexpected and maternal deaths) (58.2\%), unexpected loss of a limb or a function (14.8\%), major medication errors (7.4\%) and retained instruments or sponges (7.4\%).

Figure 2 shows the outcomes of the different types of sentinel events (died or survived). Death as an outcome of the sentinel event was reported in 100\% of suicide in the inpatient departments and intravascular gas embolism, 40.6\% of major medication errors, and $6.8 \%$ 

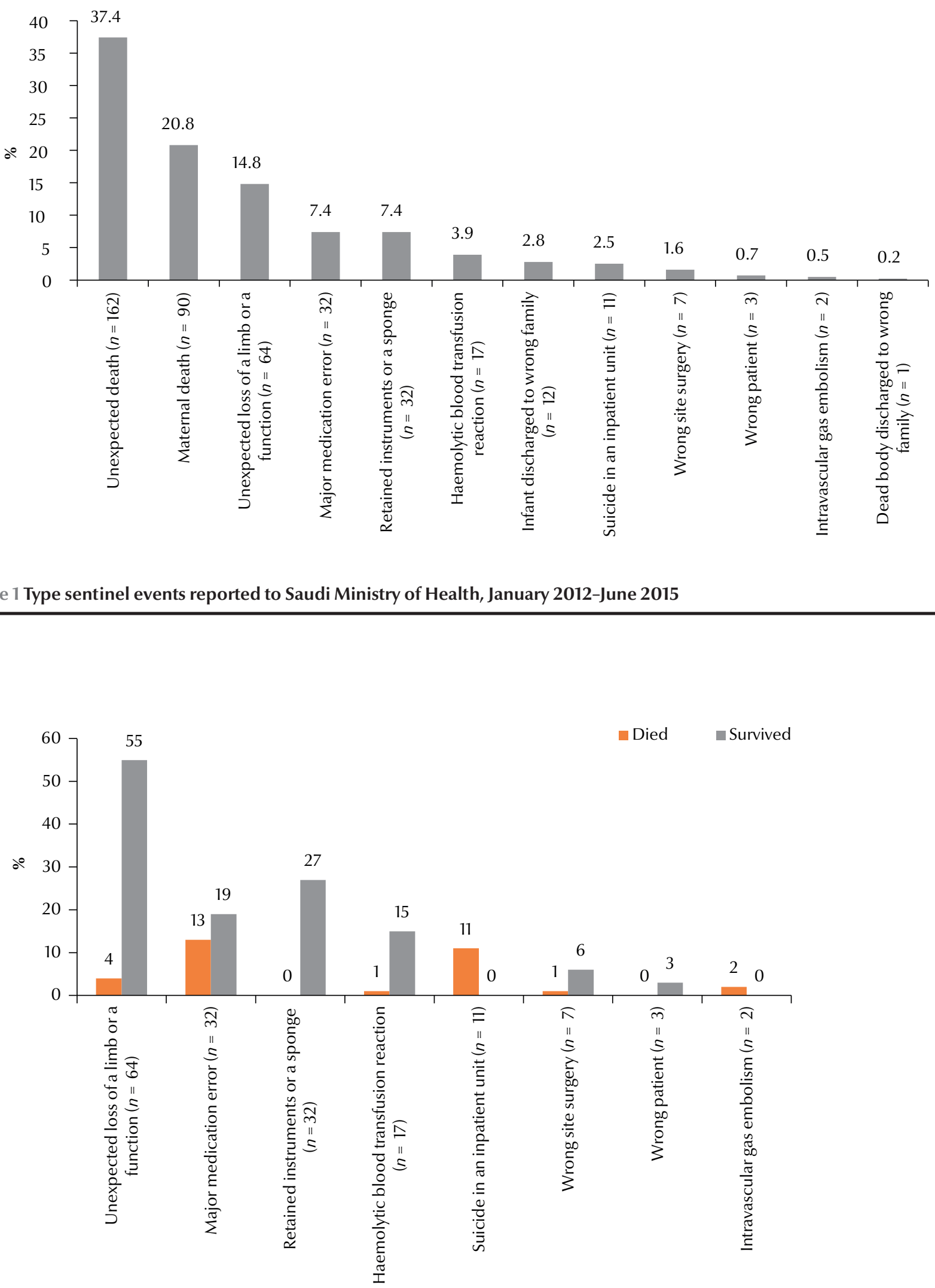

Figure 2 Outcome of primary sentinel events (excluding death as a primary event) reported to Saudi Ministry of Health, January 2012-June 2015 
of unexpected loss of limb or function. One patient each died of haemolytic blood transfusion reaction and wrong site surgery events.

Half of the reported cases were women; however, data on sex were missing for 115 (26.6\%) patients. Most of the reported cases were adults (1964 years) $(61.7 \%)$, followed by infants $<1$ year $(16.6 \%)$, children and adolescents (1-18 years) (11.7\%) and elderly patients $\geq 65$ years $(9.9 \%)$ (Table 1 ). Among the reported sentinel events, $47.9 \%$ were non-surgical interventions, $44.0 \%$ were surgical interventions and $8.2 \%$ were vaginal delivery. Most of the reported events were in government hospitals (82.4\%).

Table 1 shows the characteristics of the cases, and type of intervention and hospital by outcome (died, survived). Age 19-64 years was significantly associated with death as an outcome of sentinel events compared with infants < 1 year: OR: 2.17; 95\% CI: 1.15-4.08 ( $P$ $=0.02$ ). However, there was no significant association between death and any other age group. In addition, there was no statistically significant association between death and sex, kind of intervention or type of hospital $(P>0.05)$ (Table 1).

The majority of the reported sentinel events were classified as preventable (91.6\%). Preventable causes were identified in $95.3 \%$ of unexpected deaths, $78.3 \%$ of maternal deaths, $93.0 \%$ of unexpected loss of a limb or a function and $84.6 \%$ of retained instruments or sponges. Retained instruments would be $100 \%$ preventable; however, a malfunction of intravenous cannulas in some hospitals, which resulted in a broken tip on application, were reported as non-preventable and the manufacturers were notified $(n=4)$. Other reported sentinel events (major medication error, infant discharged to wrong family, suicide in an inpatient unit, wrong site surgery, wrong patient, intravascular gas embolism and dead body discharged to wrong family) were identified as 100\% preventable (Figure 3).
The likelihood of a non-preventable sentinel event was significantly higher among women than men: OR: 9.06; 95\%CI: $1.59-194.90(P=0.01)$. However, none of the other variables were significantly associated with sentinel event preventability $(P>0.05)$ (Table 2).

Embolism occurred in $22.8 \%$ and $31.11 \%$ of cases of maternal deaths and unexpected deaths, respectively.

Figure 4 shows the causes of the sentinel events as reported in the root cause analysis. An event was not necessarily a result of a single cause and more than one cause (e.g. availability of policy and procedures, communication, equipment) may contribute to occurrence of one event. Hence the overall percentage of the identified causes was more than $100 \%$.

Unavailability of policy and procedures and/or failure to implement them was the most common cause of sentinel events (55.0\%), followed by lack of proper communication and training (35.3\% and $33.0 \%$ respectively).

\begin{tabular}{|c|c|c|c|c|}
\hline \multirow[t]{3}{*}{ Variable } & \multicolumn{2}{|c|}{ Patient outcome } & \multirow{3}{*}{$\begin{array}{l}\text { Odds ratio ( } 95 \% \text { confidence } \\
\text { interval) }\end{array}$} & \multirow[t]{3}{*}{$P$-value } \\
\hline & Died & Survived & & \\
\hline & No. (\%) & No. $(\%)$ & & \\
\hline \multicolumn{5}{|l|}{ Sex } \\
\hline Female $(n=215)$ & $150(69.8)$ & $65(30.2)$ & Reference & \\
\hline Male $(n=98)$ & $71(72.4)$ & $27(27.6)$ & $1.14(0.67,1.96)$ & 0.64 \\
\hline \multicolumn{5}{|l|}{ Age group (years) } \\
\hline$<1(n=55)$ & $33(60.0)$ & $22(40.0)$ & Reference & \\
\hline $1-5(n=13)$ & $9(69.2)$ & $4(30.8)$ & $1.49(0.41,6.19)$ & 0.78 \\
\hline $6-18(n=26)$ & $17(65.4)$ & $9(34.6)$ & $1.26(0.47,3.44)$ & 0.66 \\
\hline $19-64(n=205)$ & $157(76.6)$ & $48(23.4)$ & $2.17(1.15,4.08)$ & 0.02 \\
\hline$\geq 65(n=33)$ & $26(78.8)$ & $7(21.2)$ & $2.45(0.92,7.04)$ & 0.07 \\
\hline \multicolumn{5}{|l|}{ Intervention } \\
\hline Non-surgery $(n=198)$ & $136(68.7)$ & $62(31.3)$ & Reference & \\
\hline Surgery $(n=183)$ & $118(64.5)$ & $65(35.5)$ & $0.83(0.55,1.27)$ & 0.38 \\
\hline Delivery $(n=34)$ & $27(79.4)$ & $7(20.6)$ & $1.75(0.74,4.56)$ & 0.21 \\
\hline \multicolumn{5}{|l|}{ Hospital } \\
\hline Government $(n=347)$ & $235(67.7)$ & $112(32.3)$ & Reference & \\
\hline Private $(n=75)$ & $52(69.3)$ & $23(30.7)$ & $1.08(0.63,1.87)$ & 0.80 \\
\hline
\end{tabular}

Data were missing for some variables. 


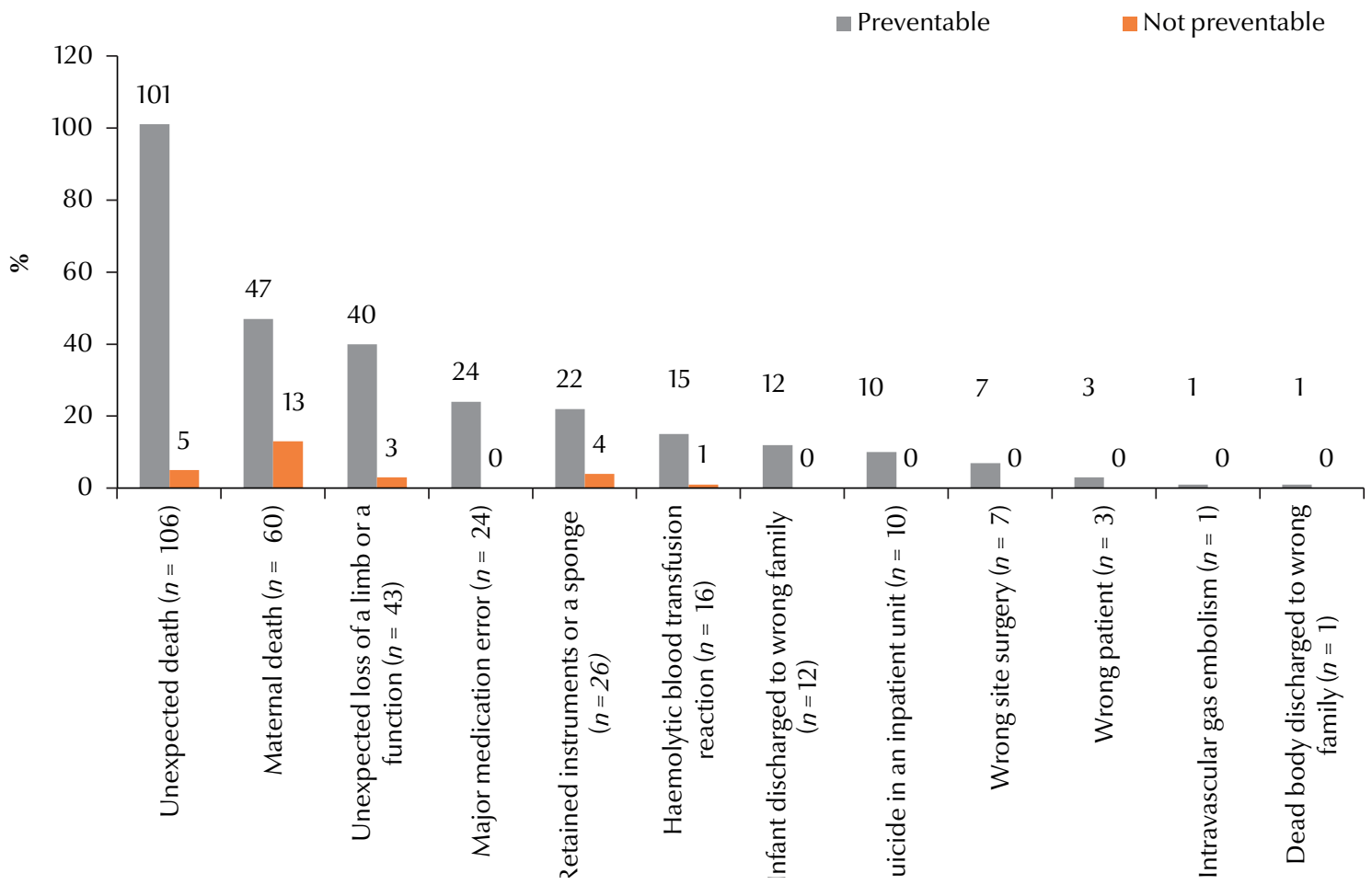

Figure 3 Distribution of the reported sentinel events according to preventability based on reports to Saudi Ministry of Health, January 2012-June 2015

About $25 \%$ of the causes were attributed to equipment/supplies and $22.2 \%$ to staffing (shortage/misallocation and/ or work overload). Other causes represented about 10\% each (delay in treatment, non-adherence to clinical practice guidelines and hospital system malfunction).

\section{Discussion}

Our study is an analysis of sentinel events in Saudi Arabia. It relied on reports sent to the $\mathrm{MOH}$ and our conclusions are dependent on the quality of documentation. It could be assumed that some of the actual events are not reported (6). Therefore, conclusions about the relative frequency of events or trends in events over time should be drawn with caution.

There were 433 reported sentinel events; most commonly reported events were deaths (representing more than half of the events), unexpected loss of a limb or a function, major medication errors and retained instruments or sponges.

The incidence of adverse and sentinel events reported in studies varies considerably. Variations are related to study setting, methodology and underlying definitions. The problem of under-reporting has a major effect on the estimated incidence as well (7). Therefore, comparison with other studies may not be always possible given the differences in the methodological designs and the reporting culture.

In hospitals in the United States of America (USA), the total number of sentinel events reported to the Joint Commission increased from 449 cases in 2000 to a peak of 1243 cases in 2011. In the following years from 2012 to mid-2015, the number of cases decreased (901, 887, 764 and 474 respectively). The most commonly reported events were unintended retention of a foreign body, fall, suicide, delay in treatment, wrong patient, wrong site, wrong procedure, operative/post-operative complication, criminal event and perinatal death or injury (8).

In a systematic review of 8 retrospective chart review studies from the USA, Canada, the United Kingdom (UK), Australia and New Zealand, permanent disability and death were found in $7.0 \%$ (inter quartile range 6.1-11.0\%) and $7.4 \%$ (inter quartile range $4.7-14.2 \%$ ) of patients respectively who experienced an adverse event [the median incidence of adverse events was $9.2 \%$ (inter quartile range $4.6-12.4 \%)$ ]. The median proportion of adverse events associated with surgical procedures was $58.4 \%$ (inter quartile range 54.5-70.9\%) (9). This was higher than another study which reported that $44.9 \%$ of the adverse events were related to surgical interventions (10). When it comes to critical areas (e.g. intensive care units), the magnitude of the problem could be underestimated, although as estimated 


\begin{tabular}{|c|c|c|c|c|}
\hline \multirow[t]{3}{*}{ Variable } & \multicolumn{2}{|c|}{ Preventability } & \multirow{3}{*}{$\begin{array}{l}\text { Odds ratio (95\% } \\
\text { confidence interval) }\end{array}$} & \multirow[t]{3}{*}{$P$-value } \\
\hline & Not preventable & Preventable & & \\
\hline & No. (\%) & No. (\%) & & \\
\hline \multicolumn{5}{|l|}{ Sex } \\
\hline Male $(n=75)$ & $1(1.3)$ & $74(98.7)$ & Reference & \\
\hline Female $(n=155)$ & $17(11.0)$ & $138(89.0)$ & $9.06(1.59,194.9)$ & 0.01 \\
\hline \multicolumn{5}{|l|}{ Age group (years) } \\
\hline$<1(n=47)$ & $1(2.1)$ & $46(97.9)$ & Reference & \\
\hline $1-5(n=9)$ & $0(0.0)$ & $9(100.0)$ & - & \\
\hline $6-18(n=19)$ & $1(5.3)$ & $18(94.7)$ & $2.51(0.06,101.6)$ & 0.58 \\
\hline $19-64(n=151)$ & $16(10.6)$ & 135 (89.4) & $5.42(0.93,117.8)$ & 0.11 \\
\hline$\geq 65(n=20)$ & $0(0.0)$ & $20(100.0)$ & - & \\
\hline \multicolumn{5}{|l|}{ Intervention } \\
\hline Non-surgery $(n=146)$ & $9(6.2)$ & 137 (93.8) & Reference & \\
\hline Surgery $(n=137)$ & $13(9.5)$ & $124(90.5)$ & $1.59(0.65,4.01)$ & 0.30 \\
\hline Delivery $(n=23)$ & $4(17.4)$ & $19(82.6)$ & $3.17(0.78,11.25)$ & 0.16 \\
\hline \multicolumn{5}{|l|}{ Hospital } \\
\hline Government $(n=275)$ & $21(7.6)$ & $254(92.4)$ & Reference & 0.28 \\
\hline Private $(n=34)$ & $5(14.7)$ & $29(85.3)$ & $2.08(0.65,5.73)$ & \\
\hline
\end{tabular}

by Cullen et al., the incidence of adverse events in intensive care units was nearly twice the rate of other units (11)

Our findings showed that elderly people ( $\geq 65$ years) and adults were at higher risk of death as an outcome of sentinel events than newborns and children. In a national study in Spain, elderly people ( $\geq 65$ years) were at a 2.5 greater risk of adverse events than younger age groups (12), while in a Moroccan study, adverse events occurred more frequently in younger patients, which the authors attributed to the increased self-medication among younger people (7).

Our study showed that embolism caused $23-31 \%$ of the maternal and unexpected deaths. Attention should be given to this finding with further review of medical practices, including identification of patients at risk of embolism and implementation of evidence-based prevention interventions. The Saudi Arabian $\mathrm{MoH}$ has published guidelines on the prevention of post-surgical pulmonary embolism; however, adherence to these guidelines is not known.
We judged the preventability of an event based on the investigation of each case and assessment of the information available on the presence of a modifiable cause of harm or a lack of adherence to guidelines. Wefound a high frequency of preventable events (range 78.3-100\%). Negligence of people and system errors that could be prevented at the time of the event were difficult to identify. In a study in the Eastern Mediterranean and African regions, $83 \%$ of adverse events were considered preventable (13). Differences in study design and types of sentinel events should be taken into consideration when comparing the findings with our study. We also found that non-preventable events were higher among women, which could be attributed to adverse effects of labour and delivery interventions.

The incidence of preventable adverse events differs in various studies. It ranged from $18.7 \%$ to $73.2 \%$ in a review of the literature by Kanjanarat et al. (14), and it was estimated that $28 \%$ of adverse events in hospitals in the USA were preventable (15). The report of a national study in Spain showed that
$42.8 \%$ of the adverse events could have been prevented (12). De Vries et al. reported a similar rate in their systematic review, where $43.5 \%$ of the adverse events were judged preventable (inter quartile range 39.4-49.6\%) (9). A worrying number of patients experienced permanent disability or death as a result of these events (9). In addition, events due to negligence, defined as adverse events caused by a failure to meet standards reasonably expected of the average physician or institution, were not considered in the preventability calculation (9). In the Harvard Medical Practice Study I, one third of the adverse events were attributed to negligence (16).

A lack of policies and procedures, inappropriate communication, lack of staff training, and issues of equipment and supplies and staffing (whether because of shortages or allocation or scheduling) were all important causes of sentinel events; together they represented $80 \%$ of the causes. These issues clearly need to be tackled in order to improve the health care and patient safety in the reporting hospitals. The root cause analysis of the sentinel events 


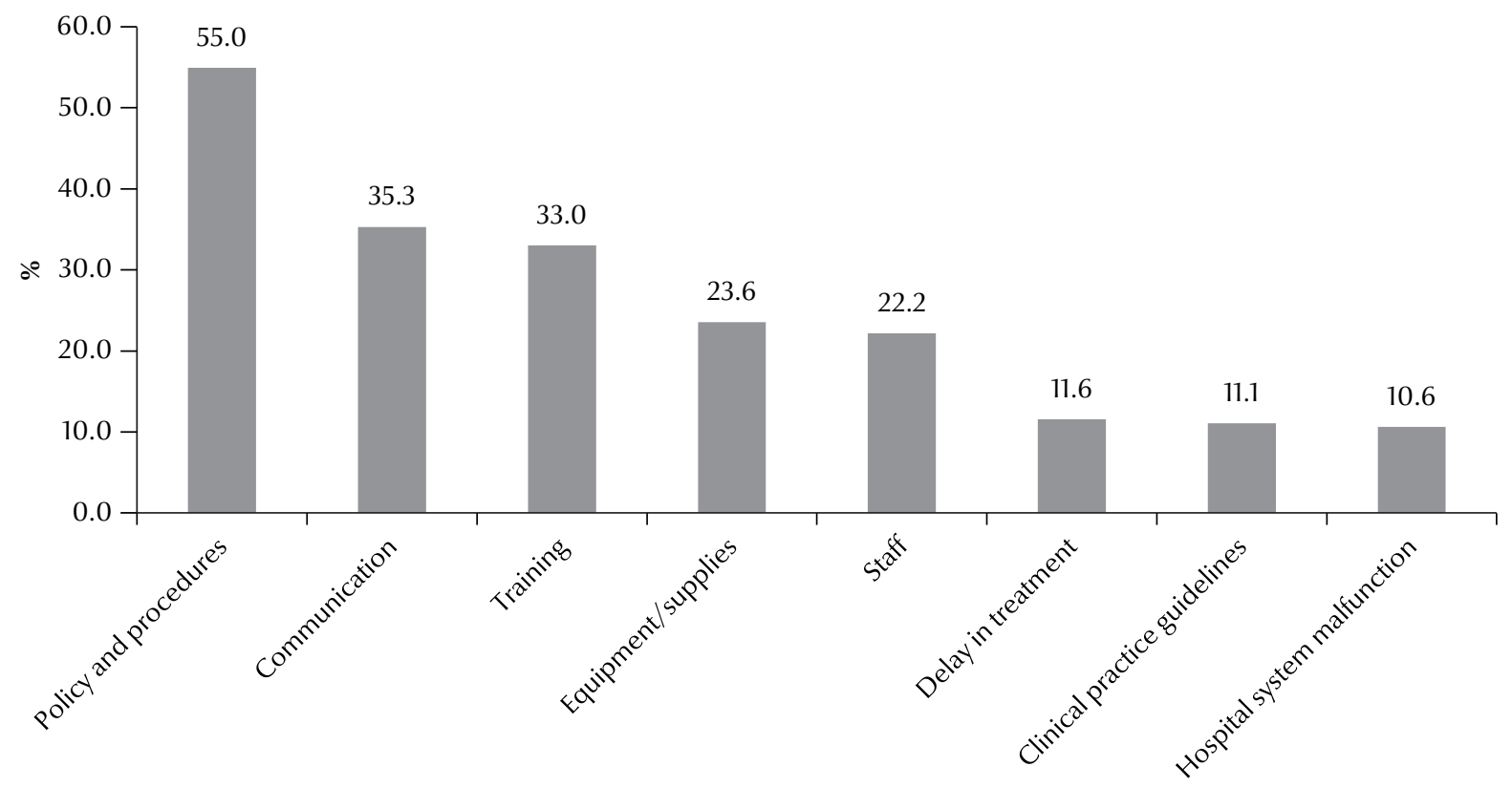

Figure 4 Cause of the sentinel events based on reports to Saudi Ministry of Health, January 2012-June 2015

in our study showed consistency with the patient safety study conducted the Eastern Mediterranean and African regions (13) with some variations, primarily due to study design differences.

The ultimate value of sentinel events reporting is communication of lessons learned to the stakeholders and the public. Examples are the National Patient Safety Agency which is the UK national reporting system (17) and standards/ resources by the Joint Commission for sentinel events reporting, aggregation, analysis, and communication. The Saudi Central Board for Accreditation of Healthcare Institutions in combination with the $\mathrm{MoH}$ aims to make health care facilities better equipped to actively eliminate the risk of sentinel events or at least to reduce the risk. The Saudi Arabia $\mathrm{MoH}$ adopted an electronic portal for reporting sentinel events which is currently active; however, the effect of this portal could be improved if further analytical features were included (e.g. root cause analysis, corrective or preventive action plan and communicating lessons to the health care community). It has been shown that reliance on voluntary reporting and the lack of an effective national system for adverse events reporting and investigation lead to an increased burden on the health care system $(18,19)$.

Classen et al. found that voluntary reporting in hospitals in the USA and measuring patient safety indicators did not reflect the real incidence of adverse events within the hospitals. Using the global trigger tool of the Institute for Healthcare Improvement, at least 10 times more adverse events were found (20). Increasing incident reporting does not mean increasing events, rather dissemination of non-punitive reporting (21).

The main limitations of this study are related to its retrospective design. It may be difficult to generalize the current findings because of underreporting and because most of the reported data were from $\mathrm{MoH}$ hospitals with only a small number from private hospitals. Health care workers tend to be suspicious about the consequences of reporting and this may result in underreporting. However, the $\mathrm{MoH}$ leadership has placed a strong emphasis on the mandatory reporting of sentinel events with sanctions in cases of non-reporting.

In conclusion, this study is the first report of sentinel events in Saudi Arabia. It alerts the health care system in Saudi Arabia to the magnitude of sentinel events and the need for immediate intervention. Ensuring availability and implementation of policies and procedures, fixing the flaws in the organizational system and training of health care workers are central to improving patient safety in health care facilities. Efforts should focus on enhancing the National Sentinel Events Reporting System, conducting expert analysis of the incidents reported and building a patient safety culture that is system-oriented, nonpunitive, confidential and responsive.

\section{Acknowledgement}

Abdulrahman Albawardi, MD, Ministry of Health, Information and Communication Technology Department, Riyadh, Saudi Arabia: for providing the data reported to the $\mathrm{MoH}$ portal.

\section{Funding: None}

Competing interests: None declared. 


\section{References}

1. The Joint Commission. Sentinel Event Policy and Procedures. (http://www.jointcommission.org/Sentinel_Event_Policy_ and_Procedures/default.aspx, accessed 27 March 2017).

2. Lawtonr R, Parker D. Barriers to incident reporting in a healthcare system. Qual Saf Health Care. 2002 Mar;11(1):15-8.

3. Leapel LL, Brennan TA, Laird N, Lawthers AG, Localio AR, Barnes BA, et al. The nature of adverse events in hospitalized patients: Results of the Harvard Medical Practice Study II. N Engl J Med. 1991;324:377-84.

4. Lynn ML, Osborn DP. Deming's quality principles: a health care application. Hosp Health Serv Adm. 1991 Spring;36(1):111-20.

5. The Joint Commission. Comprehensive accreditation manual for hospitals. January 2013 (http://www.jointcommission.org/ assets/1/6/CAMH_2012_Update2_24_SE.pdf, accessed 27 March 2017).

6. National hospital standards. 3rd ed. Jeddah: Saudi Central Board for Accreditation of Healthcare Institutions (CBAHI); 2014.

7. Benkirane R, Pariente A, Achour S, Ouammi L, Azzouzi A, Soulaymani R. Prevalence and preventability of adverse drug events in a teaching hospital: a cross-sectional study. East Mediterr Health J. 2009 Sep-Oct;15(5):1145-55.

8. The Joint Commission. Sentinel event data. General Information,1995-2Q 2015 (http://www.jointcommission. org/assets/1/18/General-Information_1995 $\square 2 Q-2015 . p d f$, accessed: 27 March 2017).

9. De Vries EN, Ramrattan MA, Smorenburg SM, Gouma DJ, Boermeester MA. The incidence and nature of in-hospital adverse events: a systematic review. Qual Saf Health Care. 2008;17:216-23. 10.1136/qshc.2007.023622

10. Thomas EJ, Studdert DM, Burstin HR, Orav EJ, Zeena T, Williams $\mathrm{EJ}$, et al. Incidence and types of adverse events and negligent care in Utah and Colorado. Med Care. 2000 Mar;38(3):261-71.

11. Cullen DJ1. Sweitzer BJ, Bates DW, Burdick E, Edmondson A, Leape LL. Preventable adverse drug events in hospitalized patients: a comparative study of intensive care and general care units. Crit Care Med. 1997 Aug;25(8):1289-97.
12. National Study on Hospitalisation-Related Adverse Events (ENEAS). Report. Madrid: Ministry of Health and Consumer Affairs; 2006 (http://www.who.int/patientsafety/information_centre/reports/ENEAS-EnglishVersion-SPAIN.pdf, accessed 27 March 2017).

13. Wilson RM, Michel P, Olsen S, Gibberd RW, Vincent C, ElAssady $R$, et al. Patient safety in developing countries: retrospective estimation of scale and nature of harm to patients in hospital. BMJ. 2012 Mar 13;344:e832.

14. Kanjanarat P, Winterstein AG, Johns TE, Hatton RC, GonzalezRothi R, Segal R. Nature of preventable adverse drug events in hospitals: a literature review. Am J Health Syst Pharm. 2003 Sep 1;60(17):1750-9.

15. Bates DW, Cullen DJ, Laird N, Petersen LA, Small SD, Servi D, et al. Incidence of adverse drug events and potential adverse drug events. Implications for prevention. ADE Prevention Study Group. JAMA. 1995 Jul 5;274(1):29-34.

16. Brennan TA, Leape LL, Laird NM, Hebert L, Localio AR, Lawthers AG, et al. Incidence of adverse events and negligence in hospitalized patients: results of the Harvard Medical Practice Study I. N Engl J Med. 1991 Feb 7;324(6):370-6.

17. Vincent C. Incident reporting and patient safety: Emphasis is needed on measurement and safety improvement programmes. BMJ. 2007;(334):51.

18. Brennan TA, Gawande A, Thomas E, Studdert D. Accidental deaths, saved lives, and improved quality. $N$ Engl J Med. 2005;353(13):1405-9.

19. Milgate K, Hackbarth G. Quality in Medicare: from measurement to payment and provider to patient. Health Care Financ Rev. 2005/06;27(2):91-101.

20. Classen DC1. Resar R, Griffin F, Federico F, Frankel T, Kimmel N, Whittington JC, Frankel A, Seger A, James BC. 'Global trigger tool' shows that adverse events in hospitals may be ten times greater than previously measured. Health Aff (Millwood). 2011 Apr;30(4):581-9. 10.1377/hlthaff.2011.0190.

21. Beyea SC. Learning from sentinel event statistics. AORN J. 2004 Aug;80(2):315-8. 